\title{
TOBACCO RELATED CONTENT ON NEW MEDIA AND ITS EXPOSURE AMONG UNIVERSITY STUDENTS IN BANGLADESH
}

\author{
Md. Jahir Uddin \\ Lecturer \\ Department of Gender and Development Studies \\ Begum Rokeya University, Rangpur, Bangladesh \\ E-mail: jahir.gds@brur.ac.bd \\ Md. Azizul Islam \\ Assistant Team Co-Coordinator \\ Issheghuri Foundation, Dhaka, Bangladesh \\ E-mail: azizuldu1994@gmail.com \\ Md. Asaduzzaman Mondol Asad \\ Assistant Professor \\ Department of Public Administration \\ Begum Rokeya University, Rangpur, Bangladesh \\ E-mail: asad.pad.brur@gmail.com
}

Received: August 08, 2021 Accepted: September 20, 2021 Online Published: November 09, 2021

DOI: 10.46281/aijssr.v9i1.1430

URL: https://doi.org/10.46281/aijssr.v9i1.1430

\begin{abstract}
The study investigates the tobacco-related content on new media and its exposure among university students in Bangladesh. A cross-sectional study design based on mixed-method approach had been used to conduct this study. A sample of 405 respondents were selected from eight public universities in Bangladesh for the survey questionnaire. Besides, 20 key informant interviews were conducted with structured question, and a checklist used for new media observation regarding tobacco-related contents. Quantitative analysis performed with descriptive and inferential statistics for survey data, while thematic analysis followed for qualitative data. The study revealed that $43.5 \%$ of respondents were exposed to tobacco-related content (TRC) in New Media. Regarding exposure to TRC, Facebook (43.5\%) was on the top, followed by YouTube (39.2\%), Instagram (35.6\%), Online Newspaper (25.2\%), Blog (22.2\%) and Twitter (12.5\%). Study shows that one-fifth of the respondents (20.2\%) had an engagement with these TRC by post, share, like and comment through Facebook, YouTube, and Twitter. KII explored that TI promotes their products using names and logos, violating the TAPS ban, which was shared by new media users and exposed to university students. Finally, the study concludes that for attracting the
\end{abstract}


university students, the tobacco industry has developed different tools and techniques in new media.

Keywords: New Media, Tobacco, Contents, Exposure, University Students.

\section{LITERATURE REVIEW}

Internet users have increased considerably, and presently more than 90 million people are using the internet in Bangladesh ("Bangladesh: internet penetration rate 2019| Statista", 2021). Among the internet user's majority are associated with new media and primarily graduate students (James \& Vishwanathan, 2018). In different ways, they are getting the touch of tobacco promotional activities in new media, which badly affect the students (Hassan et al., 2019). For a strict ban on tobacco promotion in new media, it is important to explore the tobacco-related content on new media. While the tobacco-related content on new media will be investigated, then the government would be able to take the initiative to control these promotional activities, which can control large tobacco extent (Niederdeppe, Farrelly, \& Wenter, 2007). Therefore, the governments need to develop a fresh approach to combat tobacco-related content in new media (Freeman, 2012).

Historically, scientifically, environmentally, economically and from another segment, it is proved that tobacco is dangerous for human living (Yukihiro, Hiramatsu, \& Kawano, 2011). Every year 7 million people lead to death for this damaging thing and Bangladesh is one of the high-risk countries in case of tobacco activities including selling, producing, consuming (Islam \& Walton, 2019). Considering the extremely negative impact of tobacco a county of India named Tamil Nadu has taken the policies to intervene in the media for the reduction of the tobacco. By promoting the anti-tobacco program, campaign, discussion, content on new media the government of Tamil Nadu gets effective positive results in case of a reduction of tobacco uses (Raheem \& Selladurai, 2018).

In case of making people aware of the tobacco disadvantages, the media can play an advocacy role by showing the bad impact of tobacco uses (Sood, 2015). At the same time, media can increase the interaction of multiple levels of people for the development of awareness among them. Media can develop a community against smokers or other tobacco users by developing a strong relationship with young and can contribute to young smoking cessation (Niederdeppe, Farrelly, \& Wenter, 2007).

On the other hand, in USA fund has developed for an anti-smoking campaign. Here, the media is considering as the most effective tools to use this fund in the anti-smoking promotion (Tsoukalas, 2003). According to a report finding, nearly $51 \%$ of people are active users of different new media. People are getting any kind of news via new media than other media existing in the present world. Freeman (2012) in his research shows that the new media is the most effective tools for tobacco control in this $21^{\text {st }}$ century. By using the availability and cost effectiveness of new media, it is possible to reduce tobacco using large extent (Freeman, 2012).

Recently, a research paper has published about the role of mass media for controlling tobacco. This research shows that mass media can contribute by increasing people interaction in the light of tobacco control at large extent (Sadeque \& Ahmed, 2017). In addition, in Bangladesh, social media can contribute a lot, as the majority of the people who are using the internet are associated with social media. In Bangladesh, social media can be a great means for controlling or reduction tobacco uses at large extent (Turk et al., 2018).

Though some research conducted on this topic, generally those have explained the role of mass media or social media for controlling tobacco in Bangladesh. However, those studies fail to address the problem that most of the tobacco industry is using the new media covertly for tobacco 
promotion as well as fail to address the role of new media in case of tobacco control among university students. For effective uses of new media for tobacco control, it is necessary to know the pattern of tobacco promotional activities by the tobacco industry.

\section{Operational Definition}

\section{METHODOLOGY}

\section{New Media}

New media refer to the highly interactive digital technology. New media is quickly processed, stored, transformed, retrieved, hyper-linked, and, perhaps most radical of all, quickly searched for and accessed. New media refers to Facebook, Twitter, Instagram, YouTube, Tango, and Online Newspaper. Conceptually, new media can be viewed as a cultural process that reflects societal values and societal transformation (Livingstone \& Lievrouw, 2009).

\section{Tobacco-Related Contents Exposure}

Tobacco-Related contents refer the advertisement, promotional activities, sponsorship, posting of tobacco products and selling by the tobacco industries in new media place. Exposure refers the like, comments, share, post, view, invitation in tobacco page.

\section{University Students}

University students refers the graduate and post graduate students who are the regular users of new media.

\section{Study Design}

For conducting this study, the cross-sectional design followed. This research was conducted by following the mixed-method approach, both qualitative and quantitative methods.

\section{Study Area and Population}

This study covered eight public Universities of eight divisions in Bangladesh. The study populations were the university's students and regular (daily) users of new media.

\section{Study Period}

The study conducted from April to November 2019.

\section{Sampling Design}

\section{Survey}

For the quantitative part, the sample size has been calculated using the following formula: -

$$
n=\frac{P(1-P) \times Z^{2}}{d^{2}}
$$

Equation, $\mathrm{n}=405$, Where,

$\mathrm{Z}=1.96$ for $5 \%$ level of significance

$\mathrm{P}=$ Percentage of graduate students exposed to the tobacco activities on new media (Unknown) $=50 \%$

$\mathrm{d}=$ Margin of error $=0.05$ (considered)

Non-response $=5 \%$ 
For collecting data through a survey questionnaire, 405 respondents were selected from eight public universities. From those universities, respondents were being chosen randomly for the questionnaire survey. The distribution of respondents by the university are given below-

Table 1. Study Area

\begin{tabular}{|l|l|}
\hline Study Area & Number of respondents \\
\hline Dhaka University & 55 \\
\hline Chittagong University & 50 \\
\hline Shahjalal University of Science and Technology & 50 \\
\hline Barisal University & 50 \\
\hline Jatiya Kabi Kazi Nazrul Islam University & 50 \\
\hline Rajshahi University & 50 \\
\hline Begum Rokeya University & 50 \\
\hline Khulna University & 50 \\
\hline Total & $\mathbf{4 0 5}$ \\
\hline
\end{tabular}

\section{Observation}

For exploring the pattern of tobacco promotional activities using new media, contents in six new media channels have been observed rigorously. The distribution of the selected site of the new media are given below-

Table 2. New Media Observation Site

\begin{tabular}{|l|l|l|}
\hline New media & Types & Number of page/channels \\
\hline Twitter & Social networking & 1 \\
\hline Facebook & Social networking & 1 \\
\hline YouTube & Video sharing & 1 \\
\hline Blog.com & Blog publishing & 1 \\
\hline Online newspaper & News publicizing & 1 \\
\hline \multicolumn{2}{|c|}{ Total } & $\mathbf{6}$ \\
\hline
\end{tabular}

\section{Key Informant Interview (KII)}

For selecting the respondents of KII, the purposive sampling method has followed. Numbers of KII from the different segments are given below-

Table 3. Lists of KII

\begin{tabular}{|l|l|}
\hline Critical Informants Interview (KII) & Number of participants \\
\hline New Media Specialists & 5 \\
\hline Government Officials & 5 \\
\hline
\end{tabular}




\begin{tabular}{|l|l|}
\hline Anti-Tobacco Activists & 5 \\
\hline Civil Society Representatives & 5 \\
\hline Total & $\mathbf{2 0}$ \\
\hline
\end{tabular}

\section{Data Analysis}

The raw data inserted into the database system. For analyzing the collected data of this study database system had been used. For making the data analysis more thorough and suitable, the validity of the data had scrutinized. To analyze the survey data, SPSS had been used. Various statistical tools, such as descriptive statistics, correlation, cross-tabulations, central tendency tests, etc., extensively examined the data collected. Finally, the comprehensive findings of this research have presented.

\section{Ethical issues}

Institutional ethical clearances of this study acquired from the Department of Public Administration, University of Dhaka. Informed written consent had taken before conducting the interview. Individual ethical issues had maintained in every tier of the study.

\section{Quantitative Findings}

\section{RESULTS}

\section{Respondent Characteristics}

Table 4. Gender and age of the respondents

\begin{tabular}{|l|l|l|}
\hline Gender & Number & Percentage \\
\hline Male & 307 & $75.8 \%$ \\
\hline Female & 98 & $24.2 \%$ \\
\hline Total & $\mathbf{4 0 5}$ & $\mathbf{1 0 0 . 0 \%}$ \\
\hline Average age, Mean $\pm S D$ & $21.5 \pm 1.613$ & \\
\hline
\end{tabular}

The gender and age of the respondents are shown in the above table (Table 4). Among the 405 respondents, $75.8 \%$ respondents were male, and $24.2 \%$ were female. The average age of the respondents was 21.5 years old.

\section{Tobacco Using Status}

Table 5. Tobacco use status of the respondents

\begin{tabular}{|l|l|l|}
\hline Variable & Number & Percentage \\
\hline Overall Tobacco Users & & \\
\hline Yes & 81 & $20.0 \%$ \\
\hline No & 324 & $80.0 \%$ \\
\hline Total & $\mathbf{4 0 5}$ & $\mathbf{1 0 0 . 0 \%}$ \\
\hline Smoking Tobacco & & \\
\hline Yes & 77 & $19.0 \%$ \\
\hline No & 328 & $81.0 \%$ \\
\hline
\end{tabular}




\begin{tabular}{|l|l|l|}
\hline Total & $\mathbf{4 0 5}$ & $\mathbf{1 0 0 . 0 \%}$ \\
\hline Smokeless Tobacco & & \\
\hline Yes & 13 & $3.2 \%$ \\
\hline No & 392 & $96.8 \%$ \\
\hline Total & $\mathbf{4 0 5}$ & $\mathbf{1 0 0 . 0 \%}$ \\
\hline
\end{tabular}

The above table (Table 5) shows the smoking and smokeless tobacco using status of the respondents. Among the 405 respondents, $20.0 \%$ were tobacco users. Here, 19.0\%respondents consumed smoking tobacco currently, while $3.2 \%$ of respondents consumed smokeless tobacco.

Table 6. Type of smoking and smokeless tobacco

\begin{tabular}{|l|l|}
\hline Types & Percentage \\
\hline Smoking tobacco* & \\
\hline Cigarette & $100.0 \%$ \\
\hline Bidi & $7.9 \%$ \\
\hline E-cigarette & $7.9 \%$ \\
\hline Base, $\mathbf{n}$ & $\mathbf{7 7}$ \\
\hline Smokeless tobacco ${ }^{*}$ & \\
\hline Jarda & $100.0 \%$ \\
\hline Sadapata & $8.3 \%$ \\
\hline Gul & $8.3 \%$ \\
\hline Base, $\mathbf{n}$ & $\mathbf{1 3}$ \\
\hline
\end{tabular}

Note: "Multiple responses.

Types of smoking and smokeless tobacco are shown in Table 6. Among tobacco users, all the respondents consumed cigarettes, and $7.9 \%$ of respondents consumed both Bidi and E-cigarette. Among smokeless tobacco users, all the respondents' consumed Jarda, and 8.3\% finished both sadapata and guys.

\section{Uses of New Media}

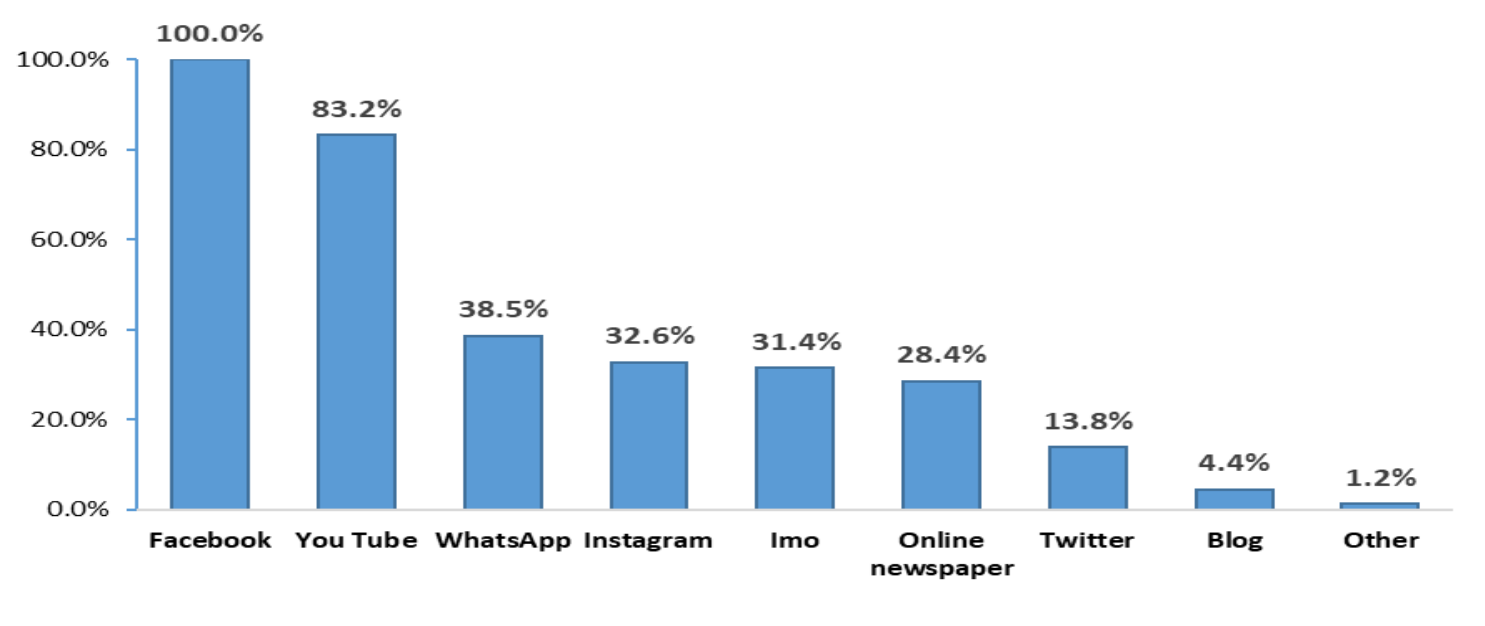

Figure 1. Type of new media/social media used by the respondents $(n=405)$ 
The above figure (Figure 1) shows different types of new media by the respondents. Among the respondents, all were Facebook users, followed by $83.2 \%$ were YouTube users, 38.5\%WhatsApp, 32.6\% Instagram, 31.4\% Imo, and 28.4\% respondents were online newspaper users. Besides, $13.8 \%$ of respondents used Twitter, some (4.4\%) used Blog, and only $1.2 \%$ used other new media types.

Table 7. TRC group/page/site/channel/news followed by the respondents on new media

\begin{tabular}{|l|l|l|}
\hline \multirow{2}{*}{ Name of new media* } & \multicolumn{2}{|l|}{ Number of TRC group/ page } \\
\cline { 2 - 3 } & $\mathbf{n}$ & Mean \pm SD \\
\hline Facebook & 405 & $0.74 \pm 1.769$ \\
\hline Twitter & 56 & $0.02 \pm 0.134$ \\
\hline You Tube & 337 & $0.66 \pm 0.1754$ \\
\hline Blog & 18 & $0.28 \pm 0.958$ \\
\hline Instagram & 132 & $0.29 \pm 0.767$ \\
\hline Online newspaper & 115 & $0.47 \pm 1.273$ \\
\hline
\end{tabular}

An average number of TRC group/page/site/channel/news followed by the respondents in new media are shown in Table 7. On average, respondents viewed 0.74 TRC in Facebook, 0.02 TRC in Twitter, 0.66 TRC channel in YouTube,0.28 TRC site in Blog, 0.29TRC page in Instagram and 0.47TRC site in Online newspaper.

\section{Promotional Activities/ Exposure to Tobacco Related Content (TRC)}

Any content on new media, which contain the different pro-tobacco scene, tobacco consumption, tobacco product, brand, and sponsorship and have not warned message, are termed as TobaccoRelated Content (TRC). Respondents were exposed to different types of TRC in video, image and text format that is shown below:

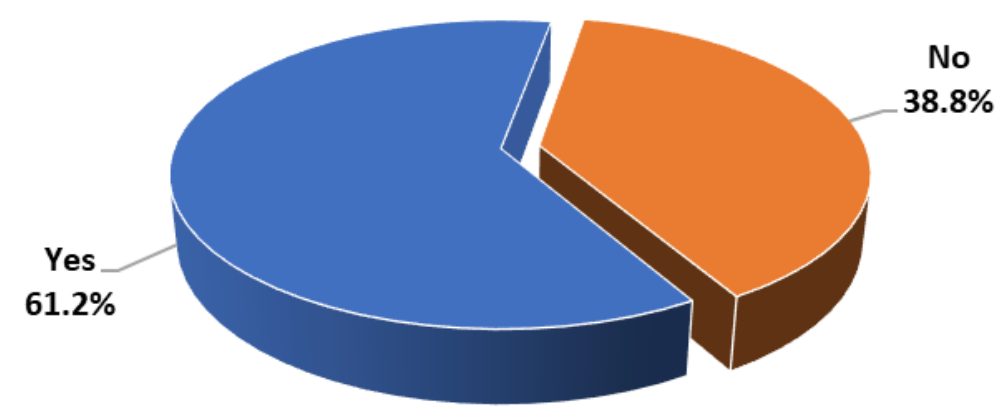

$n=248$

Figure 2. Overall exposure to TRC post in new media 
Figure 2 presents respondents overall exposure to the TRC post in new media in the last six months. It explored that $61.2 \%$ of the respondents saw the TRC post in new media while $38.8 \%$ did not.

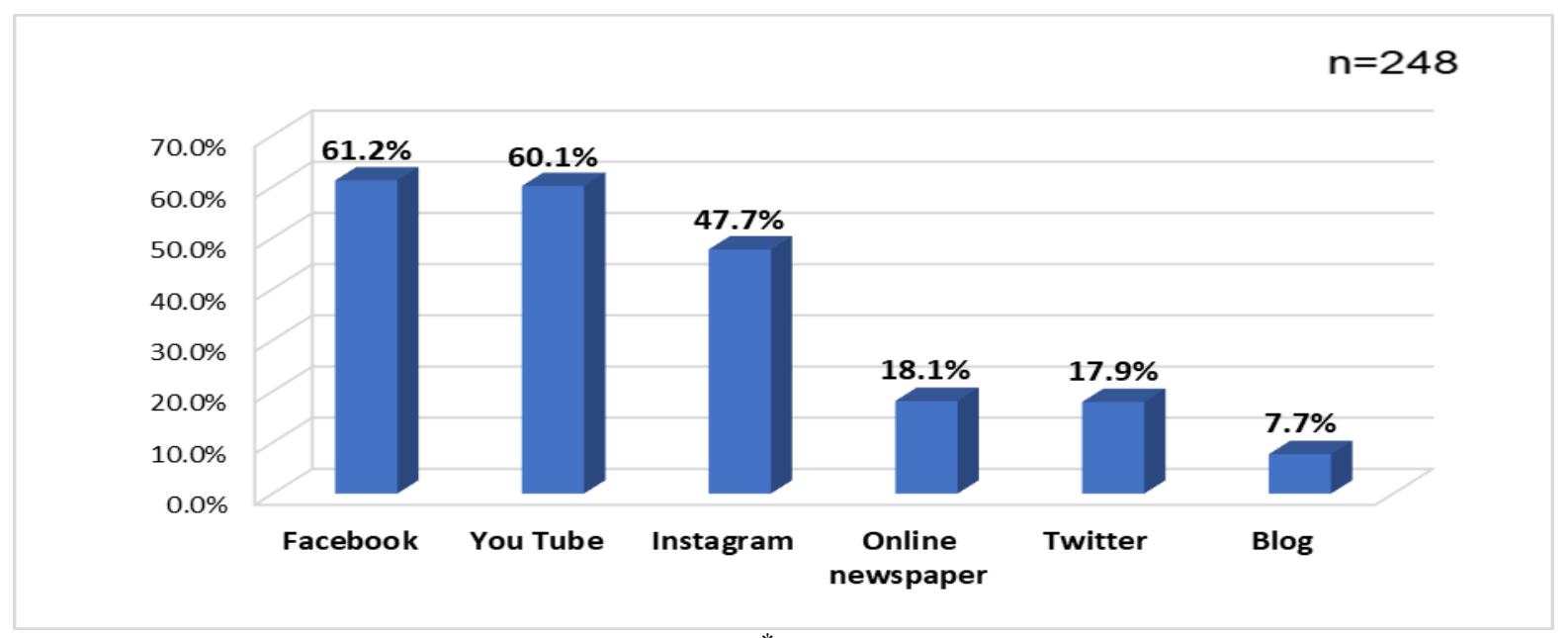

Note: *Multiple responses.

Figure 3. Respondent's exposure to TRC post by new media

The above graph (Figure 3) shows the percentage of the respondents exposed to TRC by new media. Overall, among the respondents, $61.2 \%$ exposed to TRC in the last six months on Facebook, $60.1 \%$ in YouTube, $47.7 \%$ in Instagram, $18.1 \%$ in Online newspapers, $17.9 \%$ in Twitter, and $7.7 \%$ in Twitter Blog.

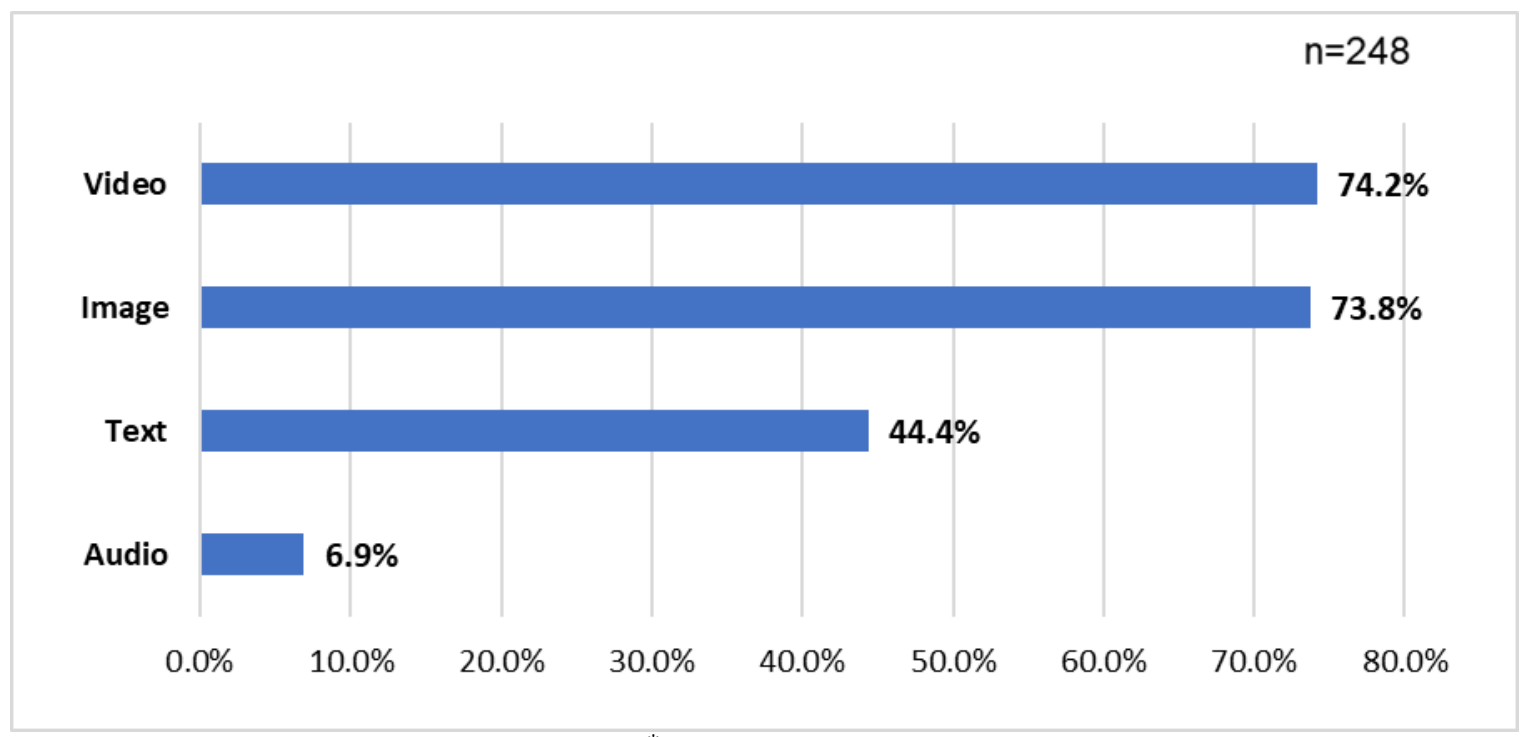

Note: * Multiple responses

Figure 4. Type of TRC post exposed by the respondents

Overall, the type of exposed TRC post is shown in Figure 4. Among the exposed TRC post, $74.2 \%$ was video, and $73.8 \%$ was the image; that is, video and image highly exposed TRC posts in new media. Again, $44.4 \%$ revealed TRC was text, and $6.9 \%$ was only audio. 


\section{Influence on Student}

Table 8. Smoking status of the respondents by overall exposure to TRC, reactions to TRC on FB/TW/IN

\begin{tabular}{|c|c|c|c|c|}
\hline \multirow[t]{2}{*}{ Variables } & \multirow[t]{2}{*}{$\mathbf{n}$} & \multicolumn{2}{|c|}{ Smoking Status } & \multirow[t]{2}{*}{ p-value } \\
\hline & & Yes & No & \\
\hline \multicolumn{4}{|l|}{ Overall exposure to TRC } & \multirow[t]{3}{*}{0.001} \\
\hline Yes & 248 & $24.6 \%$ & $75.4 \%$ & \\
\hline No & 157 & $10.2 \%$ & $89.8 \%$ & \\
\hline $\begin{array}{l}\text { Overall exposure to } \text { TRC on } \\
\text { FB/TW/IN }\end{array}$ & & & & \multirow[t]{3}{*}{0.001} \\
\hline Yes & 193 & $26.4 \%$ & $73.6 \%$ & \\
\hline No & 212 & $12.3 \%$ & $87.7 \%$ & \\
\hline \multicolumn{4}{|l|}{ Overall reactions to $\mathrm{TRC}$} & \multirow[t]{3}{*}{0.001} \\
\hline Yes & 145 & $31.7 \%$ & $68.3 \%$ & \\
\hline No & 260 & $11.9 \%$ & $88.1 \%$ & \\
\hline
\end{tabular}

Note: $p$-value from chi-square test

Table 8 shows the percentage of the respondents exposed to TRC and their tobacco smoking behavior within the last six months. It was found that among respondents who revealed to TRC, $24.6 \%$ usedsmoking tobacco. Similarly, 31.7\% respondents used smoking tobacco among them who reacted to TRC. Again, 26.4\% used smoking tobacco among the respondents exposed to TRC on Facebook, Twitter, and Instagram.

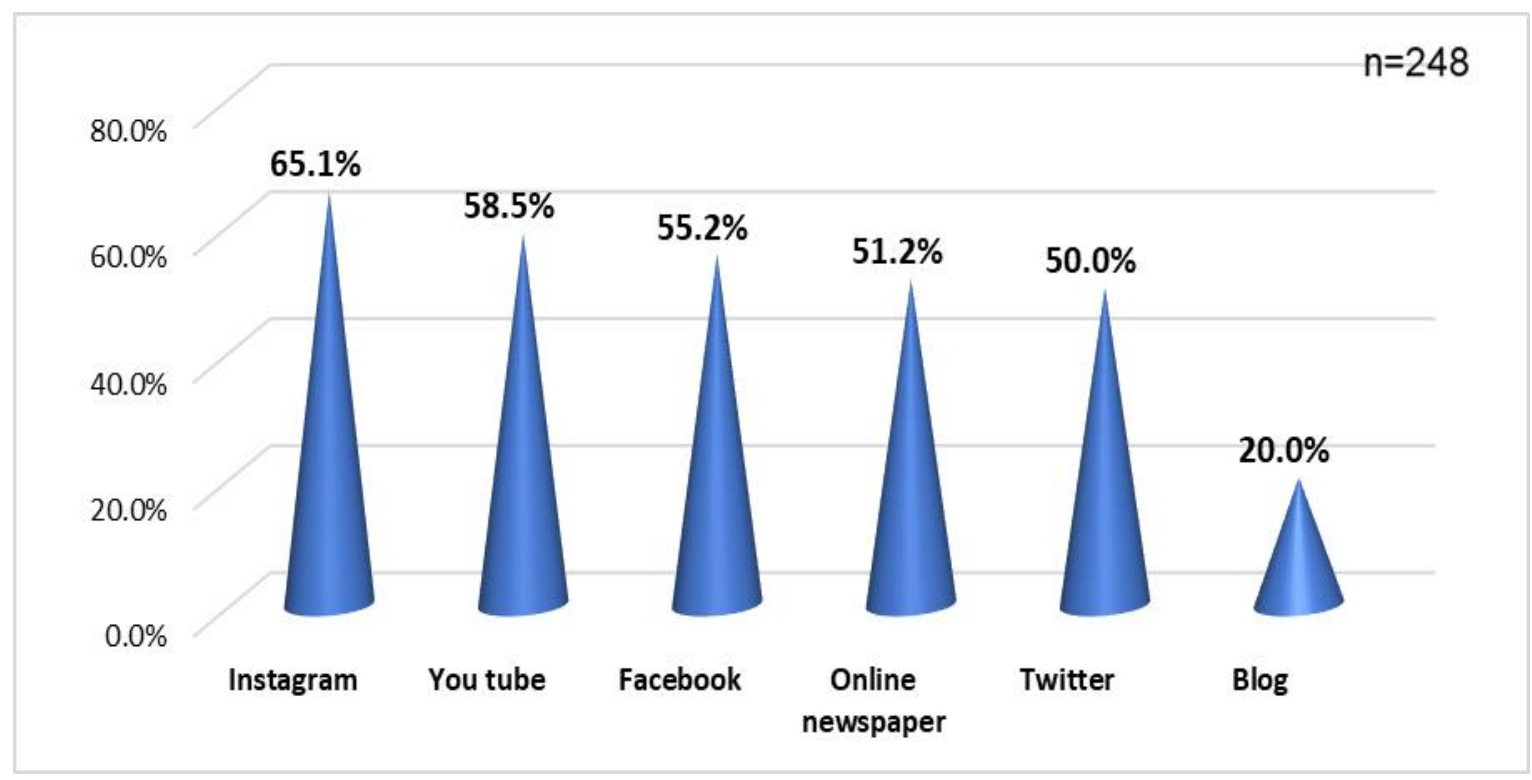

Figure 5. Percentage of respondents TRC engagement

Figure 5 shows the percentage of the respondent engagement to the TRC of the last six months based on exposure. It explored that $65.1 \%$ of respondents were engaged in Instagram, 
$58.5 \%$ in YouTube, $55.2 \%$ in Facebook, $51.2 \%$ in Online newspapers, $50.0 \%$ in Twitter, and 20.0\% in blogs through the post, share, like and comment with these TRC.

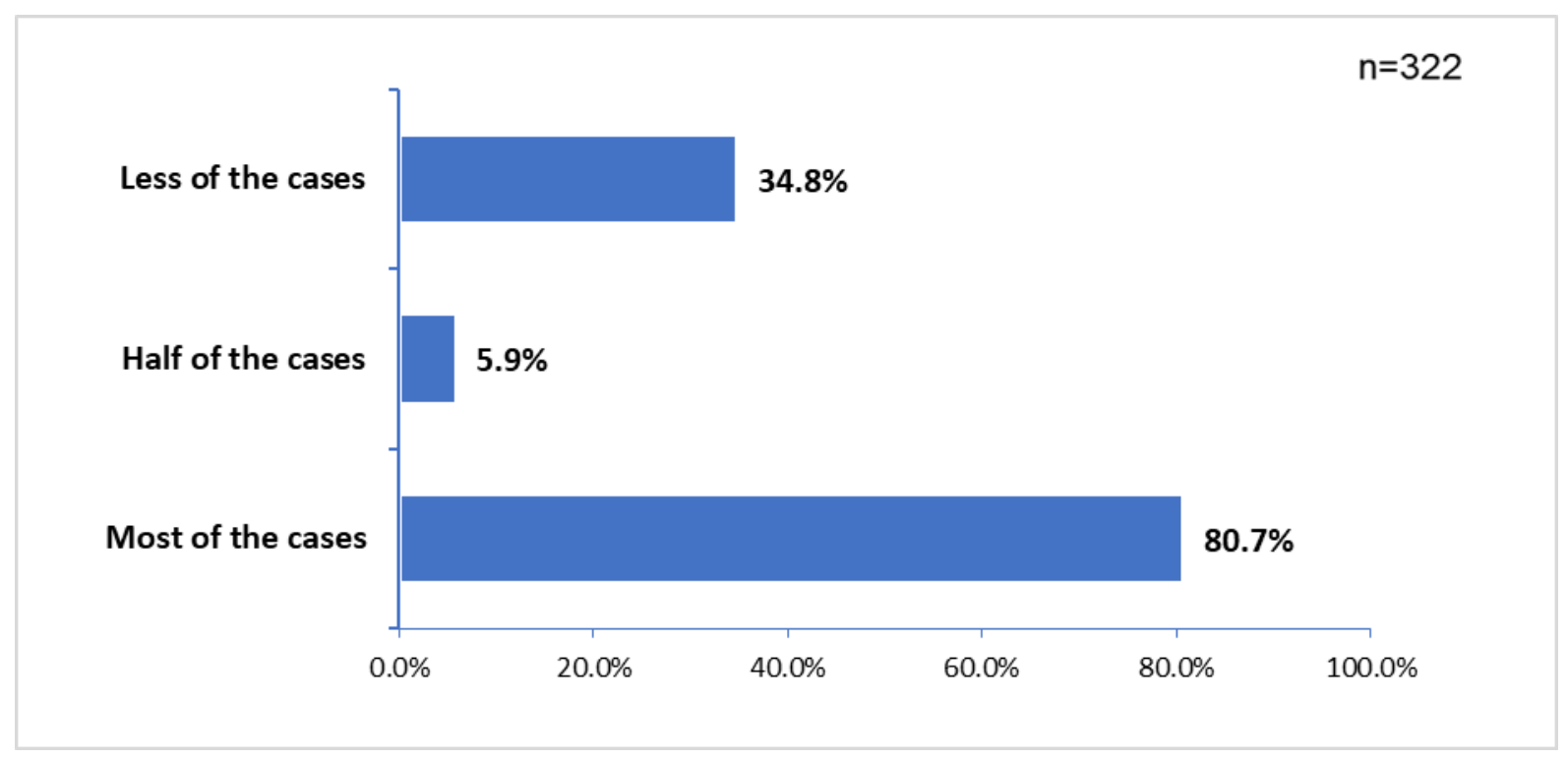

Note: *Multiple responses

Figure 6. Visibility of health warning message on the TRC of MV/D/M/CB post

The above figure (Figure 6) shows the visibility of health warning messages on the TRC of music videos, drama, movies, and celebrity's posts. Among 322 respondents, 80.7\% of respondents found health warning messages in the exposed TRC for most cases, while 34.8\% found health warning messages for fewer issues. Only $5.9 \%$ of respondents found the health warning note in the exposed TRC for half of the cases.

Table 9. Respondents who tried to consume tobacco influenced by TRC scene in new media

\begin{tabular}{|l|l|l|}
\hline Number of students & Number & Percentage \\
\hline Yes & 48 & $11.9 \%$ \\
\hline No & 357 & $88.1 \%$ \\
\hline Total & $\mathbf{4 0 5}$ & $\mathbf{1 0 0 . 0 \%}$ \\
\hline
\end{tabular}

Table 9 shows the percentage of respondents who tried to consume tobacco seen by the TRC scene in new media. It found that $11.9 \%$ of respondents tried to consume tobacco by seeing glamorous TRC scenes in new media, while $88.1 \%$ did not try. 


\section{Tobacco Control Activities in New Media}

$$
\mathrm{n}=267
$$

$80.0 \%$

$63.3 \%$

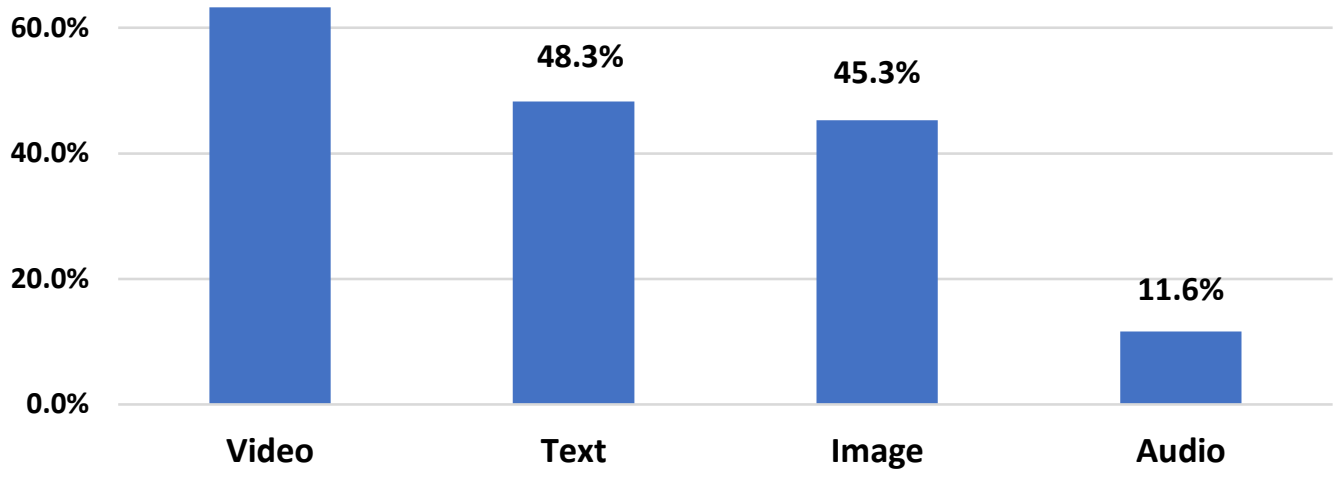

Note: *Multiple responses

Figure 7. Types of tobacco control content exposed by the respondents

Figure 7 shows the types of tobacco control content post on new media. The majority $(63.3 \%)$ of the respondent exposed to video, $45.3 \%$ to image, $48.3 \%$ to text, and $11.6 \%$ to audio on new media.

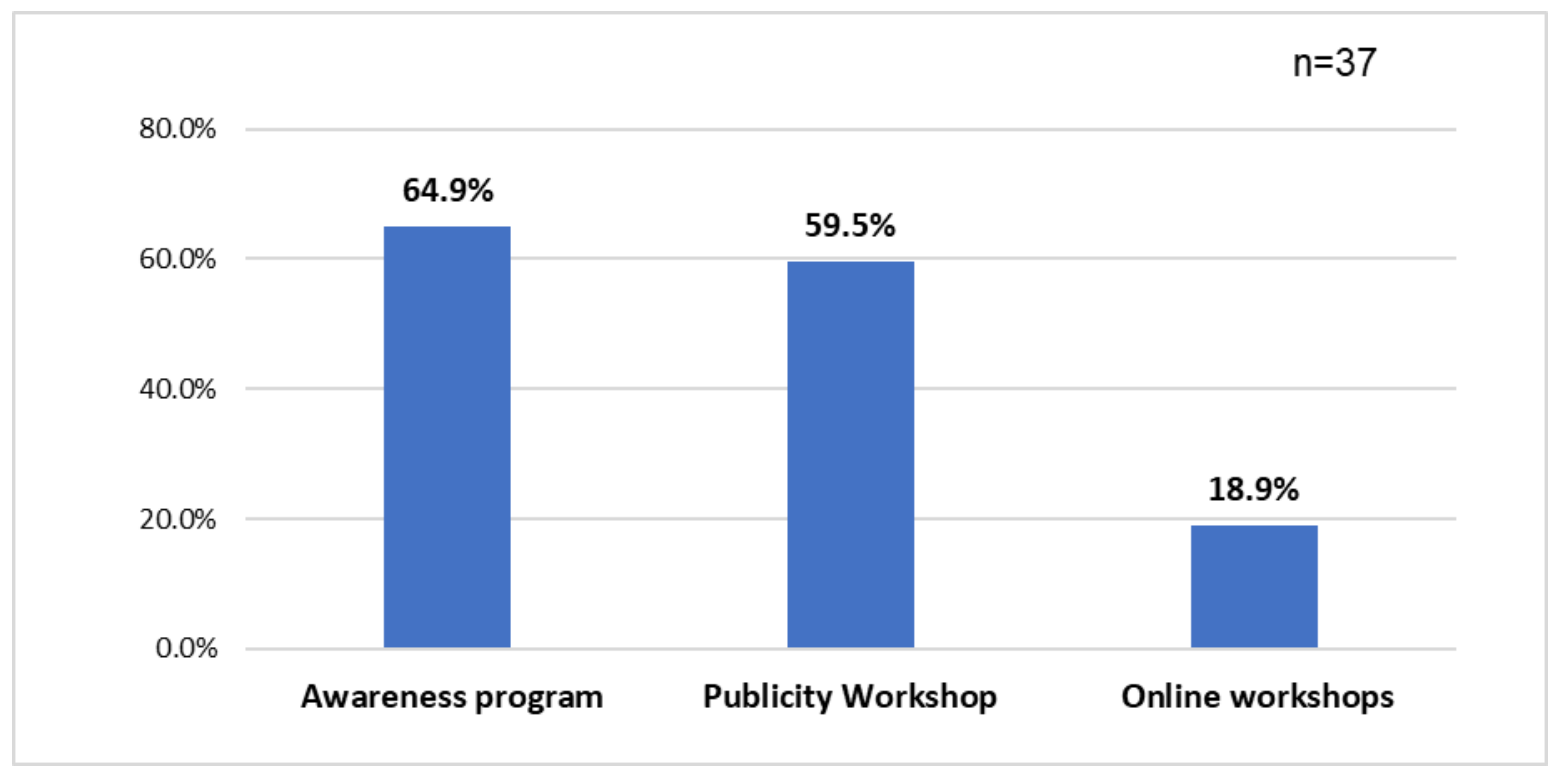

Note: *Multiple responses;

Figure 8. Type of tobacco control activities based on new media

The above graph (Figure 8) presents different types of tobacco control activities on new media. It found that $59.5 \%$ of respondents were exposed to various publicity workshops, $64.9 \%$ to awareness programs, and $18.9 \%$ to online seminars on new media. 


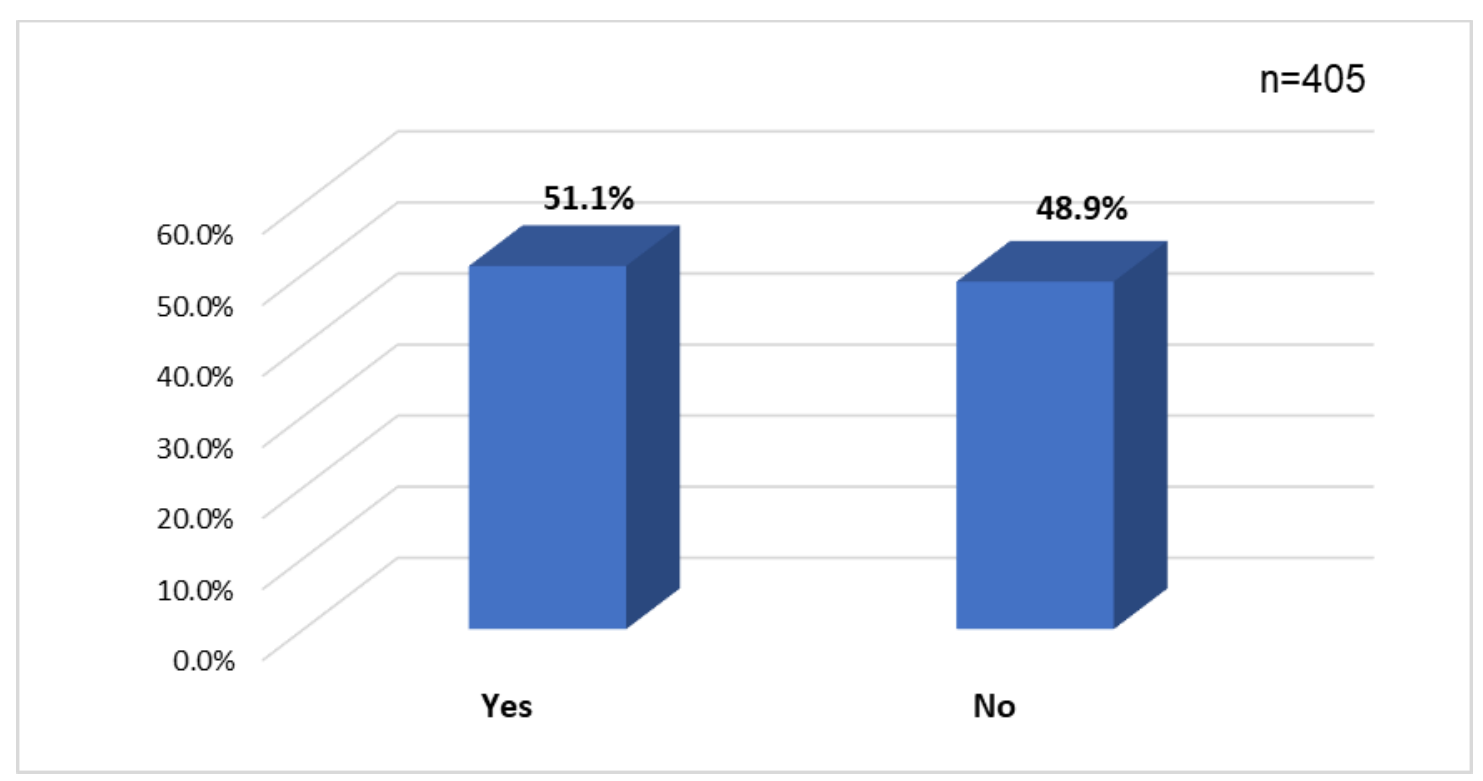

Figure 9. Respondents influenced by tobacco control activities in new media

The above figure (Figure 9) shows the percentage of respondents influenced by tobacco control programs based on new media. Almost half of the students (51.1\%) said that the tobacco control programs influenced them, and the rest of the respondents were not impacted.

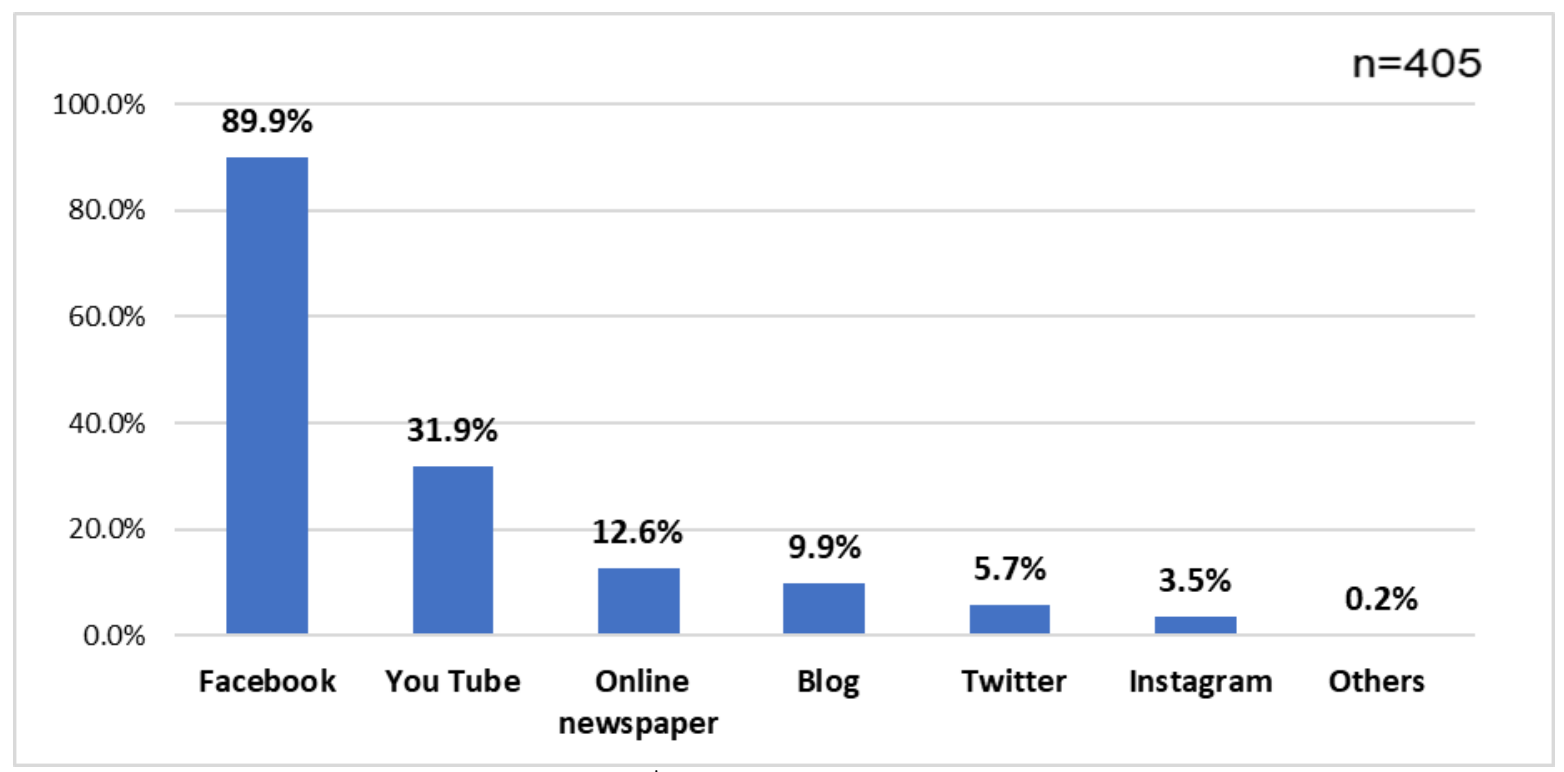

Note: *Multiple responses

Figure 10. Tobacco control-related contents by new media

The above figure (Figure 10) shows the tobacco control-related contents by new media. The highest majority (89.9\%) of the respondents were exposed to tobacco control-related content in Facebook, 31.9\% in YouTube, 12.6\% in online newspapers, 9.9\% in Blogs, 5.7\% in Twitter, and $3.5 \%$ Instagram. 


\section{Observation Findings}

\section{QUALITATIVE FINDINGS}

\section{The Pattern of Tobacco Promotional Activities}

Presently, tobacco promotional activities have taken place in the new media largely; because of the prohibition of tobacco promotional activities in Bangladesh, there is no specific inclusion of the new media. Besides, mainly Facebook, Twitter, Instagram, YouTube are using for the promotional activities of tobacco for its ease of access; similarly, the young generation or university students think smoking is part of smartness, and they upload their smoking picture in "New Media"; this, by and large, influencing the people.

The Tobacco industry cannot apply the direct techniques by using their logo, name or other things in the promotion, and if they do it, it will be an absolute crime according to the law. There may be the TI sponsorship in the different scenes of movies, drama, or YouTube videos where smoking is being shown as part of heroism. In addition, they have recruited advocates to work in favor of them for promoting their product in "New Media".

\section{Influence Over University Students}

Students are the targeted customer of the TI, and utilizing this, it becomes easy to reach and influence them. The age where the university student belongs is fascinating and wants to enjoy everything like a hero. The tobacco industries arrange different types of secret campaigns to spread the smoking tobacco. At the same time, TI hires celebrities to upload their heroism picture with smoking.

The tobacco industry has developed some characteristics in new media via video, pictures with smoking tobacco that represent bravery and heroism. The university students copy those characteristics from the video and image to become competent and valor. This copy becomes a curse for the university students to a large extent, and they began to follow those excessively.

\section{Anti-tobacco Promotional Techniques in New Media}

Some organizations, individuals, and the government have taken some initiative for the tobacco control activities in new media. Though it has become the biggest platform, it is not using essentially by the anti-tobacco activists, individuals, and government.

For the anti-tobacco promotional activities, different kinds of patterns are being followed. The designs are seminars, symposiums, awareness programs, drama and those are posted directly in the new media like Facebook, Twitter etc. Within a short time, it becomes easier to reach many populations. At the same time, the new media developed a scope where all kinds of opposing sides of tobacco become possible to telecast in detail.

\section{Government's Role in Combating Tobacco Promotional Activities by Using New Media}

The study depicts that government can play a central role in combat tobacco promotional activities in new media by developing a new law related to tobacco promotional activities in the new media and can add substantial punishment for direct and indirect tobacco promotional activities in the new media. There is a problem that the tobacco sector is the second sector for large revenue generation, and here a question may arise about the role of government.

\section{DISCUSSION}

The study finds that due to advanced knowledge on technology and being young, university students are highly using new media, and TRC is spreading in new media to a large extent. Different tobacco promotional activities are visible in new media, which have distinct patterns 
such as Audio, Video, Image and Text. In new media, both individuals and industries share different tobacco-related contents and products, which are exposed very highly to the new media users. These findings meet the demand of Choudhury et al. (2018) to develop a strategy to solve this issue.

This study explored different tobacco promotional activities exposed to university students on which they have significant reactions. It agrees with James and Vishwanathan (2018) study finding regarding tobacco among university students. A substantial number of respondents (61.2\%) were exposed to TRC by new media within the last 6-month where Facebook is on the top list. Since the previous 6-month TRC exposure, the use of smoking tobacco was found significantly higher among the respondents who exposed to TRC $(24.6 \%$ vs $10.2 \% ; \mathrm{p}<0.01)$ and who engaged with TRC $(36.5 \%$ vs $10.1 \%$; $\mathrm{p}<0.001)$ compared to who did not. It indicates that these TRC are contributing to increasing the number of smokers among university students, which needs to draw attention, reflecting the study finding of (Hassan et al., 2019). It means Facebook is one of the easiest ways to promote different tobacco products by targeting young customers.

Individuals and the tobacco industries are also using the other new media to reach the young new media users. Among the respondents who exposed different TRC on new media tend to engage with these in the post, share, like and comment. As a result, these TRC remain visible on new media for a long time and creates a positive attitude and belief about tobacco products, especially smoking tobacco. Non-smoker students are also exposed to TRC on new media and seeing different glamorous TRC posts by their virtual friends. They have tended to post and share TRC following their peer groups to get popularity (like and comment) among friends. As a result of one stage, they have the chance to addict to tobacco.

However, this study explored that any tobacco industries are not directly connected with these TRC, but there may be an indirect link for further research. Although Tobacco industries are not directly affiliated with these TRC in many ways, their name, logo, and glamorous tobacco products are visible with these exposed TRC, which found on the homepage of the respondents on new media. It found that among the exposed TRC, one-fourth of the TRC are clearly showing different tobacco industries name and logo, brands and color that determined from the last 6-month exposure post.

In addition, the new media become an essential segment for the anti-tobacco promotional activities. This supports the finding of Arsenijević and Andevski (2015) regarding making people conscious about tobacco using social media. This study finds that the majority viewed different anti-tobacco promotional activities on Facebook, Twitter, Instagram, Blog, and YouTube. However, various anti-tobacco promotional activities are visible in new media, but student engagement is shallow with these activities 'student engagement.

\section{RECOMMENDATION}

- In the tobacco advertisements prohibition law, it is mandatory to include the prohibition of tobacco advertisement in new media.

- It is necessary to ensure that no TRC will be allowed to display on new media at personal and industrial levels without warning messages.

- The government of Bangladesh should take adequate measures to formulate and implement a university-based intervention program to inform students about the harmful effects of tobacco use. In addition, those programs can telecast in new media.

- It is necessary to take the initiative to include the tobacco-related program at formal university education so that they become aware deeply of its harmful effects. 
- The government can develop programs related to the harmful effects of tobacco uses regularly and can telecast those in new media via the support of different anti-tobacco activists or organizations.

- For reducing the extreme exposure of tobacco at university premises, it is essential to enforce the Smoking and Tobacco Products Usage (control) Act, 2005 and Amendment 2013 and its regulations.

- For the students who already expressed to quit smoking, it is necessary to ensure proper assistance and tools for supporting them to stop smoking tobacco forever.

- The government should take the initiative for establishing a tobacco cessation center at the university and can provide training to the health professional is students.

\section{-}

\section{CONCLUSION}

New media are the part of the modern technology, and it is easy to use. Different new media are being used mainly by individuals and industries for tobacco promotional activities, whether directly or indirectly. There is no clear direction about the prohibition of tobacco promotional activities in new media in Bangladesh. Tobacco Industries can access the targeted customer very easily by taking advantage of the loopholes of the law. One of the target markets of the TI is the young generation, and the students at the university level are youth. For attracting them, the tobacco industry has developed different tools and techniques basis on their regular activities in new media. The tobacco industries are posting, sharing tobacco-related content in new media indirectly to attract them. Indirect involvement of the Tobacco Industries is considerable in terms of user name and logo, product details, brand names, glamorous tobacco products and sponsorship of different events and movies on new media.

In addition, still, some TRC scenes are visible in music videos, dramas, movies, and other celebrities post without health warning messages. By seeing this glamorous TRC scene, university students have primarily been influenced by the tobacco promotional activities in new media which indulging them to tobacco products largely. However, it becomes easier to reach millions of people by using new media within a short time, and it would be possible to involve the majority of university students in anti-tobacco promotional activities. The governments need to support and give sponsorships in anti-tobacco promotional activities to make them more efficient and effective to make people aware regarding life threatening impact of tobacco. Besides, findings of this study would be supportive to the policy makers of the government to regulate posting, sharing tobaccorelated content in new media in Bangladesh to save the youth like university students. 


\section{ACKNOWLEDGEMENTS}

The authors are thankful to Bangladesh Center for Communication Programs (BCCP) for their technical input and Institute for Global Tobacco Control, Baltimore, USA, for their financial support from the Bloomberg Initiative. The authors are grateful to Mohammad Shamimul Islam, Team leader, JHSPH-BCCP Tobacco control program, for his direction, guidelines, \& supportive actions throughout the research project. The authors are also thankful to Dr Kapil Ahemd, Miraz Mahmud and Farzana for assisting throughout the study period.

\section{REFERENCES}

Arsenijević, J., \& Andevski, M. (2015). Media Convergence and Diversification-The Meeting of Old and New Media. Procedia Technology, 19, 1149-1155.

Choudhury, S., Walter, K., Al-Mamun, A., Jubayer, S., Bhuiyan, M., Candler, L., ... \& Sebrie, E. (2018). Monitoring compliance with the ban on tobacco advertising and promotion at the point of sale in Bangladesh (2017). Tobacco Induced Diseases, 16(1).

Freeman, B. (2012). New media and tobacco control. Tobacco control, 21(2), 139-144.

Hassan, M. S., Hossain, M. K., \& Khan, H. T. (2019). Prevalence and predictors of tobacco smoking among university students in Sylhet Division, Bangladesh. International health, 11(4), 306-313.

Islam, F. M. A., \& Walton, A. (2019). Tobacco smoking and use of smokeless tobacco and their association with psychological distress and other factors in a rural district in Bangladesh: A cross-sectional study. Journal of environmental and public health, 2019.

James, L., \& Vishwanathan, H. K. (2018). The new age of tobacco marketing: Imagery on social media. Tobacco Induced Diseases, 16(1).

Niederdeppe, J., Farrelly, M. C., \& Wenter, D. (2007). Media advocacy, tobacco control policy change and teen smoking in Florida. Tobacco control, 16(1), 47-52.

Raheem, A. C. A., \& Selladurai, N. (2018). Increase the media contribution to reduce tobacco promotion in Tamil media. Tobacco Induced Diseases, 16(1).

Sadeque, T., \& Ahmed, K. (2017). P1. 01-025 Mass Media and Tobacco in Bangladesh: An Investigation on the Role of Mass Media in the Light of Tobacco Control: Topic: Protective Factors, Risk Reduction, Smoking Cessation. Journal of Thoracic Oncology, 12(1), S463-S464.

Sood, R. (2015). The Role of Media in Tobacco Control Campaigns. Indian Journal of Dental Education, 8(1), 15-19.

Statista. (2021). Bangladesh: internet penetration rate 2019 Retrieved from https://www.statista.com/statistics/764102/internet-penetration-rate-bangladesh 
Tsoukalas, T. (2003). Development and destruction of the first state-funded anti-smoking campaign in the USA. Tobacco Control, 12(2), 214-220.

Turk, T., Negi, N. S., Svenson, D., Hussain, S. M., Islam, M. S., \& Mullin, S. (2018). Using synergised social media approaches to support tobacco control policy and cessation related behaviours in Bangladesh. Tobacco induced diseases, 16(1).

Yukihiro, M., Hiramatsu, T., \& Kawano, T. (2011). Lethal impacts of cigarette smoke in cultured tobacco cells. Tobacco induced diseases, 9(1), 1-6.

\section{Copyrights}

Copyright for this article is retained by the author(s), with first publication rights granted to the journal. This is an open-access article distributed under the terms and conditions of the Creative Commons Attribution license (https://creativecommons.org/licenses/by/4.0) 